\title{
Evaluación de métodos de extracción de ADN para detección de Listeria monocytogenes en productos cárnicos
}

\author{
Evaluation of DNA extraction methods for detection of Listeria \\ monocytogenes in meat products
}

\author{
Lina López DA, ${ }^{1 *}$ Micr, Carlos Mejía G, ${ }^{1}$ M.Sc. \\ ${ }^{1}$ Universidad de Antioquia, Escuela de Microbiología, Grupo de investigación Biotransformación, \\ Medellín, Colombia. *Correspondencia: lina_deavila@yahoo.es
}

Recibido: Mayo de 2011; Aceptado: Febrero de 2012.

\section{RESUMEN}

Objetivo. Evaluar dos procedimientos para la extracción de ADN de Listeria monocytogenes a partir de muestras de alimentos contaminados artificialmente. Materiales y métodos. Se evaluaron diferentes métodos de extracción en cultivos puros de $L$. monocytogenes. Los métodos con mejores resultados fueron evaluados en muestras de alimentos cárnicos (jamón, salchicha y chorizo) contaminados artificialmente. Para evaluar la calidad del ADN extraído se determinó la concentración de ADN, la relación A260/A280 y se amplificó el gen hlyA de L. monocytogenes por PCR. Resultados. Los métodos con solventes orgánicos y con PBS + Tween 20 permitieron obtener mayor cantidad de ADN (40 y $50 \mu \mathrm{g}$, respectivamente). En muestras de alimentos, se obtuvo ADN de mayor pureza con el método con solventes orgánicos $(p<0,005)$, pero con el método con PBS + Tween 20 se obtuvo una mayor concentración. Con ambos métodos de extracción de ADN se logró la amplificación del gen hlyA en muestras contaminadas desde 1 hasta $10^{5} \mathrm{UFC} / \mathrm{ml}$. La composición del alimento no afectó la reacción de PCR en las muestras de ADN obtenidas con los dos métodos de extracción. Conclusiones. Independientemente del método de extracción utilizado, se logró la detección del gen $h l y A$ de $L$. monocytogenes en muestras de alimentos contaminados desde 1 hasta $10^{5} \mathrm{UFC} / \mathrm{ml}$. Sin embargo, para su uso como método rutinario de diagnóstico, el método con PBS + Tween 20 es la mejor opción para la extracción de ADN, por ser un método de fácil aplicación, bajo costo y buen desempeño.

Palabras clave: ADN, Contaminación de alimentos, extracción, Listeria (Fuente:CAB). 


\section{ABSTRACT}

Objective. To evaluate two methods for extracting DNA from Listeria monocytogenes from artificially contaminated food samples. Materials and methods. The effects of different extraction methods on pure cultures of $L$. monocytogenes. The best performing methods were evaluated in artificially contaminated samples of meat products (ham, sausage and chorizo). To assess the quality of the extracted DNA, DNA concentration and A260/A280 ratio were determined, and the hlyA gene of $L$. monocytogenes was amplified by PCR. Results. The methods with organic solvents and with PBS+Tween 20 allowed to obtain more DNA (40 and $50 \mathrm{mg}$, respectively). In food samples, DNA was obtained with higher purity through the organic solvent method $(p<0.005)$, but the method with PBS+Tween 20 resulted in higher concentration. hlyA gene amplification in samples contaminated with 1 to $105 \mathrm{CFU} / \mathrm{ml}$ was obtained through both methods of DNA extraction. The composition of the food did not affect the PCR reaction in DNA samples obtained by the two extraction methods. Conclusions. Regardless of the extraction method used, the detection of hlyA gene of $L$. monocytogenes in food contaminated samples with 1 to $105 \mathrm{CFU} / \mathrm{ml}$ was achieved. However, for use as a routine diagnostic method, the method with PBS + Tween 20 is a better option for DNA extraction, as a method of easy application, low cost and good performance.

Key words: DNA, extraction, food contamination, Listeria (Source:CAB).

\section{INTRODUCCIÓN}

Listeria monocytogenes es un patógeno emergente importante asociado al consumo de alimentos; causando listeriosis en humanos, una infección que puede presentar manifestaciones clínicas graves en ancianos, recién nacidos, mujeres embarazadas y en general personas con compromiso de la inmunidad celular (1). Aunque la incidencia de listeriosis es baja con respecto a otras enfermedades transmitidas por alimentos, esta enfermedad presenta tasas de mortalidad altas (20-30\%) (2).

Los alimentos asociados con mayor frecuencia a contaminación con $L$. monocytogenes son los productos listos para consumo (quesos, productos cárnicos, ensaladas, entre otros) (3); alimentos que no son cocidos antes de su consumo y que son almacenados a temperaturas de refrigeración, las cuales son toleradas por el microorganismo, además de tener la capacidad de adaptarse a pH bajos y altas concentraciones de sales. Los mecanismos involucrados en la aparición de brotes de listeriosis son cada vez más complejos e implican un control microbiológico más estricto en el procesamiento, almacenamiento y consumo de alimentos, es por esto que agencias internacionales como la Food and Drug Administration (FDA) de Estados Unidos de América y la Australia New Zealand Food Authorithy (ANZFA) mantienen políticas de tolerancia cero para este microorganismo (3).

La identificación de L. monocytogenes tradicionalmente se ha realizado por aislamiento en medios selectivos seguido de identificación bioquímica y serológica. Sin embargo, esta metodología ha mostrado algunas desventajas para la detección del microorganismo, principalmente por: (i) los bajos niveles de contaminación, (ii) la presencia de microbiota competidora que puede enmascarar la presencia de L. monocytogenes (4), (iii) los resultados erróneos debido a cambios en las características fenotípicas de la cepa aislada por su exposición a condiciones extremas (5) y (iv) la metodología es laboriosa y requiere de cinco a quince días para obtener resultados (6).

Con el objetivo de mejorar las estrategias de control microbiológico de $L$. monocytogenes en los alimentos, la industria exige métodos rápidos, altamente sensibles y específicos; y los métodos moleculares ofrecen excelentes características para su aplicación en este control microbiológico. Estos métodos ofrecen mayores ventajas puesto que el $A D N$ es afectado en menor medida por los cambios ambientales y permite la detección de este tipo de microorganismos de manera más precisa, además estos métodos detectan cantidades mínimas de ácidos nucleicos de manera rápida y sensible.

Desde su introducción, la Reacción en Cadena de la Polimerasa (PCR) ha demostrado ser una poderosa técnica para la detección rápida, específica y sensible de microorganismos patógenos en alimentos (7). Sin embargo, esta técnica presenta algunas limitaciones por la falta de un método estandarizado de extracción y purificación de ADN a partir de diferentes matrices alimenticias. La presencia de ciertos compuestos del alimento (fenoles, glicógeno, grasas y otras sustancias orgánicas) pueden actuar como inhibidores de la PCR dando origen a resultados falsos negativos $(8,9)$. 
López - Evaluación de métodos de extracción de ADN para determinar Listeria monocytoenes 3171

El objetivo de este estudio fue evaluar diferentes procedimientos para la extracción de ADN de $L$. monocytogenes a partir de muestras de productos cárnicos contaminados artificialmente para la amplificación por PCR del gen $h l y A$, codificante de la enzima listeriolisina $O$, responsable en gran medida de la capacidad patogénica de $L$. monocytogenes.

\section{MATERIALES Y MÉTODOS}

Muestras y medios de cultivo. Las muestras de alimentos empleadas en este estudio fueron productos cárnicos obtenidos en expendios locales. Para el crecimiento bacteriano y el enriquecimiento de las muestras de alimentos se utilizaron los siguientes medios de cultivo: Caldo CASO (Merck, Alemania); Caldo de enriquecimiento para Listeria (Listeria enrichment broth, LEB); Agar PALCAM (Oxoid, UK). Todos los medios de cultivo fueron reconstituidos y suplementados de acuerdo con las recomendaciones de los productores.

Inóculo y preparación de las muestras. La cepa de referencia utilizada fue $L$. monocytogenes ATCC 7644. Los productos cárnicos empleados para la contaminación artificial fueron jamón, salchicha y chorizo. Este procedimiento se realizó con diferentes concentraciones de $L$. monocytogenes ( 1 hasta $10^{5} \mathrm{UFC} / \mathrm{ml}$ ) de la siguiente manera: Se pesaron $2.5 \mathrm{~g}$ del alimento y se homogenizaron en un digestor de cuchilla por $30 \mathrm{~s}$ con $22.5 \mathrm{ml}$ de Caldo de LEB. A los alimentos homogenizados se adicionaron $2.5 \mathrm{ml}$ de una suspensión bacteriana de concentración conocida (1 a $10^{5} \mathrm{UFC} / \mathrm{ml}$ ). Las suspensiones bacterianas fueron obtenidas por diluciones seriadas en agua peptonada de un cultivo de $L$. monocytogenes en Caldo Tripticasa Soya (TSB), y el recuento fue confirmado por siembra en Agar Plate Count (PCA). Como control negativo se utilizó el alimento homogenizado sin contaminar. Las muestras contaminadas fueron incubadas a $30^{\circ} \mathrm{C}$ por 24 horas, se tomaron alícuotas de $1 \mathrm{ml}$ y se centrifugaron a $6500 \mathrm{~g}$ por $10 \mathrm{~min}$. El pellet obtenido fue utilizado para la extracción de ADN.

Extracción de ADN. Inicialmente se evaluaron cuatro métodos de extracción en muestras de cultivo puro y a partir de los resultados obtenidos se definieron los métodos de extracción aplicados en matrices cárnicas. Los métodos evaluados fueron:

Ebullición en presencia de Tritón X-100 (10). El pellet fue resuspendido en $50 \mu$ l de una solución de Tritón X-100 al $2 \%$ y $50 \mu$ l de agua desionizada estéril, se incubó a $100^{\circ} \mathrm{C}$ por $10 \mathrm{~min}$ y se centrifugó a $16000 \mathrm{~g}$ por $10 \mathrm{~min}$. El sobrenadante fue recuperado y almacenado $\mathrm{a}-20^{\circ} \mathrm{C}$.

Ebullición en presencia de PBS 1X + Tween 20 $0.05 \%$ (11). El pellet fue lavado dos veces con $1 \mathrm{ml}$ de PBS $1 \mathrm{X}$ ( $\mathrm{pH}$ 7.4). Posteriormente fue resuspendido en $100 \mu$ de PBS + Tween 20 $0.05 \%$, se incubó a $100^{\circ} \mathrm{C}$ por 10 min y luego se centrifugó a $16.000 \mathrm{~g}$ por $10 \mathrm{~min}$. El sobrenadante fue recuperado y almacenado a $-20^{\circ} \mathrm{C}$.

Lisis con tampón $\mathrm{KCl}(12)$. El pellet se lavó con $1 \mathrm{ml}$ de $\mathrm{NaCl} 0.85 \%$ y se resuspendió en $200 \mu \mathrm{l}$ de tampón $\mathrm{KCl}$ (Tris- $\mathrm{HCl} 20 \mathrm{mM}, \mathrm{pH} 8.0$ y KCl $50 \mathrm{mM}$ ), se incubó a $100^{\circ} \mathrm{C}$ por $25 \min$ y se centrifugó a $16000 \mathrm{~g}$ por $10 \mathrm{~min}$. El sobrenadante fue recuperado y almacenado $\mathrm{a}-20^{\circ} \mathrm{C}$.

Extracción con solventes orgánicos. La extracción orgánica se realizó de acuerdo con el método estándar descrito por Sambrook y Rusell (13). El pellet fue resuspendido en $50 \mu$ de sodio dodecil sulfato (SDS) $10 \%(\mathrm{p} / \mathrm{v})$ y $50 \mu \mathrm{l}$ de tampón de lisis $(50 \mathrm{mM}$ Tris-HCl pH 8.0, $50 \mathrm{mM}$ EDTA $\mathrm{pH}$ $8,0,1 \%(\mathrm{p} / \mathrm{v})$ SDS, $50 \mathrm{mM} \mathrm{NaCl})$. Después de 30 min a $37^{\circ} \mathrm{C}$, el $A D N$ se extrajo con 2 volúmenes de fenol, mezclado por $30 \mathrm{~s}$ y centrifugado a $16000 \mathrm{~g}$ por $10 \mathrm{~min}$. La fase acuosa se transfirió a un nuevo tubo y se adicionó un volumen igual de cloroformo, se mezcló y se centrifugó nuevamente. La fase acuosa se transfirió a un nuevo tubo y se adicionaron 2.5 volúmenes de etanol absoluto frio, se mezcló por inversión y se centrifugó por $10 \mathrm{~min}$. El etanol fue descartado y se permitió su completa evaporación. El pellet de ADN fue resuspendido en $100 \mu \mathrm{l}$ de tampón TE (10 mM Tris-HCl pH 8.0, 1 mM EDTA pH 8.0).

Para la extracción de ADN a partir de las muestras de alimentos contaminados artificialmente se evaluaron los métodos de ebullición con PBS + Tween 20 y el método de extracción con solventes orgánicos.

Calidad y cantidad de ADN extraído. Para determinar la calidad y cantidad del ADN extraído, las muestras fueron evaluadas en un espectrofotómetro (Genesys 2.0) a 260 y 280 $\mathrm{nm}$ para determinar la concentración de ADN y de proteínas, respectivamente; además, la relación A260/A280 fue calculada. Los análisis espectrofotométricos también permitieron evaluar la cantidad de ADN en cada muestra (13).

\footnotetext{
Amplificación de ADN y análisis electroforéticos. Para determinar la calidad del ADN extraído para análisis moleculares se estandarizó la PCR para la detección de un fragmento de $234 \mathrm{pb}$ del gen hlyA de $L$. monocytogenes. Los iniciadores escogidos
} 
para esta PCR fueron: Directo LMA: 5 '-CGGAGGTTCCGCAAAAGATG-3' y reverso LMB 5' -CCTCCAGAGTGATCGATCTT-3’ (14). La mezcla de reacción fue la siguiente: $1 \mathrm{U}$ de Taq polimerasa, tampón de reacción $1 \mathrm{X}, \mathrm{MgCl}_{2} 4 \mathrm{mM}$ (Fermentas), dNTPs 1,25 mM (Bioline), 20 pmol de cada iniciador y $5 \mu$ l de la muestra de ADN, en un volumen final de $25 \mu \mathrm{l}$. El perfil de temperaturas fue el siguiente: una desnaturalización inicial a $94^{\circ} \mathrm{C}$ por $5 \mathrm{~min}, 35$ ciclos compuestos por un paso de desnaturalización a $94^{\circ} \mathrm{C}$ por $30 \mathrm{~s}$, un paso de alineamiento a $55^{\circ} \mathrm{C}$ por $45 \mathrm{~s}$, un paso de extensión a $72^{\circ} \mathrm{C}$ por $45 \mathrm{~s}$, y una extensión final a $72^{\circ} \mathrm{C}$ por $7 \mathrm{~min}$. Los productos de PCR fueron visualizados por electroforesis en gel de agarosa al $1.8 \%(\mathrm{p} / \mathrm{v})$. Las muestras fueron corridas por $1 \mathrm{~h}$ y fueron teñidas con $2 \mu \mathrm{l}$ de EzVision ${ }^{\circledR}$ (Amresco, Estados Unidos), utilizado como tampón de carga. Los geles fueron visualizados en un fotodocumentador GelDoc XR (BioRad, USA).

Análisis estadístico. Los métodos de extracción de ADN de cultivo puro de L. monocytogenes y de muestras de productos cárnicos contaminados artificialmente fueron realizados por triplicado.

Las determinaciones de la cantidad y calidad del ADN obtenido con los diferentes métodos de extracción fueron evaluadas estadísticamente con un análisis de Varianza (ANOVA) en un diseño multifactorial con dos factores: tipo de alimento y métodos de extracción de ADN .Los análisis estadísticos se realizaron en el software STATGRAPHICS PLUS Versión 5.1

\section{RESULTADOS}

En el momento de definir un protocolo de extracción de ácidos nucleicos, la pureza y calidad del ADN obtenido constituyen variables importantes a tener en cuenta, principalmente en la detección de microorganismos basada en PCR. La calidad y cantidad de ADN extraído con los protocolos evaluados a partir de cultivo puro no revelaron diferencias estadísticamente significativas $(p=0.6911)$. Con el método de extracción con Tritón X-100 no se logró la amplificación del gen $h l y A$ de $L$. monocytogenes en muestras de cultivo puro por lo tanto fue excluido de los análisis. De acuerdo con estos resultados, los métodos seleccionados para la extracción de ADN a partir de muestras de alimentos contaminados con L. monocytogenes fueron los métodos con solventes orgánicos y con PBS + Tween 20; porque estos métodos lograron las mayores recuperaciones de ADN en cultivo puro (40 y $50 \mu \mathrm{g}$, respectivamente).

Las mediciones espectrofotométrica de las muestras extraídas de alimentos (Tabla 1) indican que con el método de solventes orgánicos se obtuvo muestras de ADN de mayor pureza que con el método de PBS + Tween $20(p<0.005)$; sin embargo, el ADN recuperado por ambos métodos permitió la amplificación del gen hlyA por PCR. Aunque la pureza del ADN obtenido con solventes orgánicos fue mejor, la concentración de ADN fue mayor en el método con PBS + Tween 20.

El límite de detección y la reproducibilidad de ambos métodos fueron evaluados con el

Tabla 1. MediciónA260/A280 de ADN obtenido a partir de cultivo puro de L. monocytogenes

\begin{tabular}{lccc}
\hline PROTOCOLO & \multicolumn{1}{c}{$\begin{array}{c}\text { MEDICIÓN } \\
\text { ESPECTROFOTOMÉTRICA }\end{array}$} & $\begin{array}{c}\text { CONC. DE } \\
\text { ADN }(\boldsymbol{\mu g} / \\
\boldsymbol{\mu l})\end{array}$ \\
\hline & $\mathbf{2 6 0} \mathbf{~ n m}$ & $\begin{array}{c}\text { RELACIÓN } \\
\text { A260 / 280 }\end{array}$ & \\
\cline { 2 - 3 } Tritón X-100 & 2.098 & 0.949 & -- \\
$\begin{array}{l}\text { Buffer KCL } \\
\text { PBS + Tween 20 }\end{array}$ & 0.664 & 1.550 & 0.34 \\
$\begin{array}{l}\text { Solventes orgá- } \\
\text { nicos }\end{array}$ & 0.673 & 1.718 & 0.52 \\
\hline
\end{tabular}

CONC. = CONCENTRACIÓN

procesamiento de muestras contaminadas con 1 hasta $10^{5} \mathrm{UFC} / \mathrm{ml}$ de $L$. monocytogenes por triplicado. En la figura 1, se puede observar la amplificación de una banda de 234 pb correspondiente al gen $h / y A$ en todas las muestras evaluadas, indicando que esta metodología es capaz de detectar bajos niveles de contaminación en este tipo de alimentos ( $1 \mathrm{UFC} / \mathrm{ml}$ ).

Para determinar el método de extracción más adecuado para el procesamiento de muestras

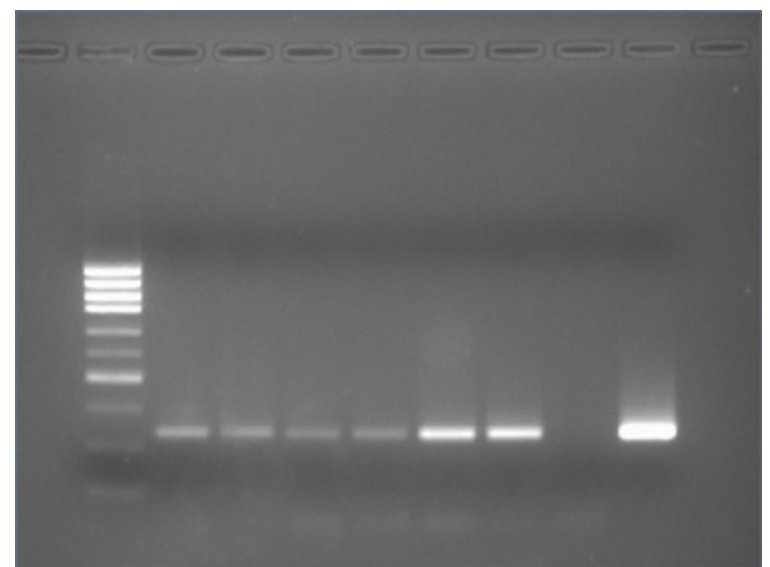

Figura 1. Amplificación un fragmento de $234 \mathrm{pb}$ del gen hlyA de L. monocytogenes. Carril M: marcador de peso molecular (GeneRuler 100 bp DNA ladder, Fermentas); Carriles L1-L6: muestras de 1 hasta $105 \mathrm{UFC} / \mathrm{mL}$ de L. monocytogenes; Carril L7: control negativo; Carril L8: cultivo puro de $L$. monocytogenes. 
de productos cárnicos, se realizaron ensayos de PCR con muestras de ADN obtenidas por ambos métodos de extracción. El producto de $234 \mathrm{pb}$ específico para L. monocytogenes fue visualizado en todas las muestras contaminadas independiente del método de extracción de ADN utilizado. En particular, en las muestras extraidas a partir de salchicha se observaron bandas de amplificación más definidas y de mayor intensidad. No se presentaron amplificaciones inespecificas y se pudo comprobar la ausencia de compuestos inhibidores de la PCR, lo que demuestra que los métodos de extracción fueron eficaces en la eliminación de componentes del alimento y del medio de enriquecimiento que puedan interferir con la reaccion de PCR. En la tabla 2 se describe el desempeño de los dos métodos de extracción evaluados en las matrices cárnicas.

Tabla 2. Comparación de protocolos de extracción de ADN a partir de muestras contaminadas artificialmente

\begin{tabular}{|c|c|c|}
\hline & $\begin{array}{l}\text { Solventes } \\
\text { orgánicos }\end{array}$ & $\begin{array}{c}\text { PBS + } \\
\text { Tween } \\
20\end{array}$ \\
\hline Tiempo requerido $(\mathrm{h})$ & $3 \mathrm{hr}$ & $1 \mathrm{hr}$ \\
\hline \multicolumn{3}{|c|}{ ADN extraído $(\mu g)$ (media \pm DS $)$} \\
\hline Jamón & $59 \pm 0.6$ & $54 \pm 0.4$ \\
\hline Chorizo & $59 \pm 0.3$ & $95 \pm 0.8$ \\
\hline Salchicha & $50 \pm 0.5$ & $79 \pm 0.3$ \\
\hline \multicolumn{3}{|l|}{$\begin{array}{l}\text { Pureza ADN }\left(A_{260} / A_{280}\right) \\
(\text { media } \pm D S)\end{array}$} \\
\hline Jamón & $1.47 \pm 0.87$ & $1.34 \pm 0.64$ \\
\hline Chorizo & $1.53 \pm 0.36$ & $1.34 \pm 0.79$ \\
\hline Salchicha & $1.27 \pm 0.42$ & $1.22 \pm 0.13$ \\
\hline
\end{tabular}

El procedimiento microbiológico estandar para la detección de L. monocytogenes en productos cárnicos descrito por la FDA (15) permitió la deteccion correcta de la presencia de $L$. monocytogenes en todas las muestras contaminadas, desde 1 a $10^{5} \mathrm{UFC} / \mathrm{ml}$.

\section{DISCUSIÓN}

La detección de $L$. monocytogenes en alimentos, especialmente en productos listos para consumo representa un gran reto, dadas las características de adaptación del microorganismo y la importancia de obtener resultados en poco tiempo que permitan la toma acertada de decisiones frente a la liberación de lotes de alimentos en las industrias productoras. Las técnicas convencionales involucran procedimientos prolongados y laboriosos de enriquecimiento, aislamiento e identificación bioquímica y serológica. Además, pueden generar resultados falsos negativos en muestras con una alta carga de microbiota acompañante que puede enmascarar la presencia de $L$. monocytogenes. Estudios previos demostraron que $L$. innocua crece a una tasa mayor que $L$. monocytogenes en medios selectivos de enriquecimiento (16), y altas concentraciones de $L$. innocua pueden inhibir el crecimiento de $L$. monocytogenes durante el enriquecimiento inicial (17).

Los avances en biología molecular han permitido el desarrollo de técnicas con características mejoradas para la detección de patógenos asociados a alimentos; sin embargo, estas metodologías se han visto limitadas por varios factores que han hecho difícil su estandarización y uso de forma rutinaria. El principal obstáculo en la aplicación de la PCR para la detección de microorganismos presentes en los alimentos es la presencia de compuestos que pueden actuar como inhibidores de la reacción de amplificación y arrojar resultados falsos negativos (18).

En este estudio, se evaluaron dos métodos no comerciales de extracción de ADN a partir de productos cárnicos. La comparación de estos métodos se basó en la rapidez, rango de aplicación, facilidad de operación y eficiencia. Se incluyeron protocolos basados en calentamiento y extracción con solventes orgánicos. Los protocolos basados en calentamiento son de bajo costo, pero el ADN extraído con estos métodos puede ser inestable por la presencia de enzimas que pueden degradarlo, además de presentar turbidez que afecta las mediciones espectrofotométricas, por lo que deben ser empleados en muestras con baja cantidad de sólidos suspendidos (19). El método clásico de extracción de ADN con solventes orgánicos posee algunas desventajas relacionadas con el uso de compuestos tóxicos, es muy laborioso y pérdida accidental de ADN. Sin embargo, continúa siendo el método de elección en el procesamiento de todo tipo de muestras.

Para evaluar el desempeño de los protocolos de extracción de ADN en diferentes matrices cárnicas, se emplearon los siguientes alimentos: chorizo, con un alto contenido graso; jamón, que contiene gran cantidad de proteínas; y salchicha, con valores similares de grasa y proteínas, compuestos reconocidos como inhibidores de la PCR (20). Con los dos protocolos evaluados se obtuvo ADN genómico que permitieron la amplificación del gen $h l y A$ de $L$. monocytogenes, aunque los valores de la relación A260/A280 fueron relativamente bajos para todas la muestras. Es importante tener en cuenta que los compuestos contaminantes en las muestras de ADN no tuvieron un efecto inhibitorio sobre la PCR. Además, se logró detectar la presencia de $L$. monocytogenes en todas las muestras, 
aún en aquellas provenientes de la más baja concentración bacteriana (1 UFC/ml antes del enriquecimiento).

Debido a la gran complejidad que representan las matrices alimenticias para la aplicación de técnicas de identificación molecular, se han evaluado diferentes protocolos de extracción de ADN de acuerdo al tipo de microorganismo y alimento. Kits de extracción comerciales han sido evaluados en diferentes matrices; el DNeasy Tissue kit (Qiagen $\mathrm{GmhH}$, Hilden, Alemania) se ha utilizado en una gran variedad de alimentos mostrando un buen desempeño en términos de pureza del ADN aunque la concentración obtenida es mucho menor que con métodos caseros (4). Otros kit de extracción que han sido evaluados para su aplicación en alimentos son el PrepMan Ultra (Applied Biosystems, Norwalk) y el kit InstaGene Matrix (BioRad, Hercules, California), y aunque los resultados obtenidos son aceptables para la identificación molecular de patógenos en alimentos, su costo elevado hace que sean difíciles de implementar en el diagnóstico de rutina.

Los métodos caseros de extracción de ADN han demostrado mayor factibilidad de aplicación por su bajo costo y buenos resultados obtenidos en diferentes matrices. En un estudio se empleó la extracción de ADN con tampón PBS + Tween 20 en muestras de quesos; obteniendo limites de detección entre 1 y10 UFC/ml (11). Se han evaluado diferentes microorganismos patógenos en alimentos con diferentes metodologías: Escherichia coli, Salmonella Typhimurium, L. monocytogenes, entre otros. Los resultados obtenidos en la identificación simultánea de estos patógenos han mostrado detecciones de $<50$ UFC/g de alimento (21).
Los métodos comparados en este estudio demostraron un buen desempeño en la extracción de ADN, con la detección de $1 \mathrm{UFC} / \mathrm{ml}$ de $L$. monocytogenes en diferentes alimentos cárnicos. Sin embargo, el método de extracción con PBS + Tween 20 presentó varias ventajas entre las que se destacan la facilidad de operación, rapidez del procedimiento y mayor cantidad de ADN extraído, además de la ventaja de no utilizar compuestos tóxicos.

La cantidad de ADN extraída con PBS + Tween 20 fue significativamente mayor que la cantidad obtenida con solventes orgánicos $(p<$ 0.005), y el tipo de alimento evaluado influyó significativamente $(p=0.034)$ en la concentración de ADN, siendo mayor en muestras de jamón que en las muestras de chorizo, posiblemente por la gran cantidad de grasas que pueden atrapar el ADN y evitar su purificación. Esta ha sido una de las grandes dificultades en la aplicación de metodologías moleculares en el diagnóstico de patógenos en alimentos, los componentes de cada alimento pueden afectar de manera diferente el desempeño del método.

En conclusión, la identificación molecular de L. monocytogenes empleando el protocolo de extracción con PBS + Tween 20 mostró un límite de detección bajo, requiriendo insumos de bajo costo y poca experticia en el desarrollo de técnicas moleculares, por lo tanto puede ser aplicado al diagnóstico de rutina de este microorganismo en productos cárnicos, productos frecuentemente asociados con la ocurrencia de listeriosis.

Es necesario evaluar metodologías rápidas de extracción como ésta en diferentes alimentos para lograr la estandarización posterior de protocolos de identificación molecular de patógenos en alimentos.

\section{REFERENCIAS}

1. McLauchlin J, Mitchell RT, Smerdon, WJ, Jewell, K. Listeria monocytogenes and listeriosis: a review of hazard characterization for use in microbiological risk assessment of foods. Int J Food Microbiol 2004; 92:15-33.

2. Ramaswamy V, Cresence VM, Rejitha J, Lekshmi MU, Dharsana KS, Prasad SP et al. Listeria-review of epidemiology and pathogenesis. J Microbiol Immunol Infect 2007; 40:4-13.
3. Swaminathan B, Gerner-Smidt P. The epidemiology of human listeriosis. Microbes Infect 2007; 9:1236-1243.

4. Amagliani G, Giammarini C, Omiccioli E, Brandi G, Magnani M. detection of Listeria monocytogenes using a comercial PCR kit and different DNA extraction methods. Food Cont 2007; 18:1137-1142. 
López - Evaluación de métodos de extracción de ADN para determinar Listeria monocytoenes 3175

5. Liu D. Preparation of Listeria monocytogenes specimens for molecular detection and identification. Int J Food Microbiol 2008; 122:229-242.

6. Norton D. Polymerase chain reactionbased methods for detection of Listeria monocytogenes: toward Real-Time screening for food and environmental samples. J AOAC Int 2002; 85(2):505-515.

7. Lukinmaa S, Nakari UM, Eklund M, Siitonen A. Application of molecular genetic methods in diagnostics and epidemiology of foodborne bacterial pathogens. APMIS 2004; 112(11-12): 908-929.

8. Hyeon J, Hwang I, Kwak H, Park C, Choi IS, Seo K. Evaluation of PCR inhibitory effect enrichment broths and comparison of DNA extraction methods for detection of Salmonella Enteriditis using real-time PCR assay. J Vet Sci 2010; 11(2):143-149.

9. Li W, Drake M. Development of quantitative competitive PCR assay for detection and quantification of Escherichia coli O157: H7 cells. Appl Environ Microbiol 2001; 67(7):3291-3294.

10. Abolmaaty A, Vu C, Oliver J, Levin R. Development of a new lysis solution for releasing DNA from bacterial cells for DNA amplification by polymerase chain reaction. Microbios 2000; 101(400):181-189.

11. Longhi C, Maffeo A, Penta M, Petrone G, Seganti L, Conte MP. Detection of Listeria monocytogenes in Italian.style soft cheese. J Appl Microbiol 2003; 94:879-885.

12. Kaclíkova $E$, Pangallo D, Drahovská $H$, Oravcová K, Kuchta T. Detection of Listeria monocytogenes in food, equivalent to en ISO11290-I or ISO 10560 , by a three days polymerase chain reaction-based method. Food Cont 2003; 14:175-179.

13. Sambrook J, Russel D. Molecular cloning: A laboratory manual. 3 edition, NY, USA: Cold Springer Harbor; 2001.
14. Aznar R, Alarcon B. PCR detection of Listeria monocytogenes: a study of multiple factors affecting sensitivity. J Appl Microbiol 2003; 95:958-966.

15. Gasanov U, Hughes D, Hansbro Ph. Methods for the isolation and identification of Listeria spp. and Listeria monocytogenes: a review. FEMS Microbiol Rev 2005; 29:851-875.

16. Bruhn J, Vogel B, Gram L. Bias in the Listeria monocytogenes enrichment procedure: lineage 2 strains outcompete lineage 1 strains in University of Vermont selective Enrichments. Appl Environ Microbiol 2005; 71(2):961-967.

17. Yokoyama E, Shibusawa Y, Maruyama S, Katsube Y, Mikami T. Influence of bacteriocinlike substance, generation times, and genetic profiles of Listeria innocua on the isolation of Listeria monocytogenes. Comp Immunol Microbiol Infect Dis 2005; 28(3):177-186.

18. Wilson IG. Inhibition and facilitation of nucleic acid amplification. Applied Environmental Microbiology 1997; 63 (10):3741-3751.

19. Elizaquivel P, Aznar R. Comparison of four commercial DNA extraction kits for PCR detection of Listeria monocytogenes, Salmonella, Escherichia coli O157:H7, and Staphylococcus aureus in fresh, minimally processed vegetables. J Food Prot 2008; 71(10):2110-2114.

20. Demeke $T$, Jenkins $R$. Influence of DNA extraction methods, PCR inhibitors and quantification methods on real-time PCR assay of biotechnology-derivaded traits. Anal Bioanal Chem 2010; 396:1977-1990.

21. Kim J, Demeke T, Clear R, Patrick S. Simultaneous detection by PCR of Escherichia coli, Listeria monocytogenes and Salmonella Typhimurium in artificially inoculated wheat grain. Int J Food Microbiol 2006; 111:21-25. 